\title{
Impact on patient care time and tumor stage of a program for fast diagnosis and treatment of colorectal cancer
}

\author{
K. P. Guzmán-Laura ${ }^{1}$, I. Bolíbar-Ribas ${ }^{2}$, M. T. Alepuz², D. Gonzalez ${ }^{3}$ and M. Martín \\ ${ }^{I}$ Masters in Public Health, Universidad Pompeu Fabra. ${ }^{2}$ Servei d'Epidemiologia Clínica i Salut Pública, Hospital de la \\ Santa Creu i Sant Pau. Universitat Autònoma de Barcelona. CIBER de Epidemiología y Salud Pública (CIBERESP). \\ ${ }^{3}$ Servei d'Patologia Digestiva, Hospital de la Santa Creu i Sant Pau. ${ }^{4}$ Servei d'Oncologia Mèdica, Hospital de la Santa \\ Creu i Sant Pau. Barcelona. Spain
}

\begin{abstract}
Objectives: to evaluate the effectiveness of a fast track diagnosis and treatment program for colorectal cancer $(\mathrm{CRC})$ in reducing the diagnosis to treatment interval (DTI) and tumor stage. To analyze the association between DTI and tumor stage.

Methods: a quasi-experimental study with a control group was conducted, and 156 incident cases of CRC referred through a preferential pathway between July 2005 and December 2008 in a tertiary hospital were included, after excluding those treated urgently, treated by endoscopic polypectomy only or having periodic colonoscopies. A control group of 156 patients was randomly selected from all the patients referred through habitual pathways, frequency matched by tumor location, age and year of entry. Data was analyzed with multivariate linear and logistic regression.

Results: mean DTI was 39.20 days (95\% CI: 36.21-42.42) for fast track patients and 63.40 days (95\% CI: 57.08-70.41) for controls $(p<0.001)$, and this difference persisted after multivariate analysis. The odds of having a DTI longer than 30 days was 4.79 (95\% CI: 2.19-10.51) higher for controls. There were no significant differences in tumor stage according to the pathway followed. Independently of the track followed, a DTI longer than 30 days was associated with advanced tumor stages for colon cancer, while it was associated with low stages for rectal cancer.

Conclusions: the PDTR strategy is effective in reducing DTI and may reduce patients' and relatives' anxiety. However, it is far from reaching the DTI recommended. The achieved reduction of the delay has no impact on tumor stage.
\end{abstract}

Key words (MESH): Colorectal neoplasm. Early diagnosis. Evaluation of health programs. Tumor stage. Health care process assessment.

K. P. Guzmán Laura, I. Bolíbar Ribas, M. T. Alepuz, D. Gonzalez, M. Martín. Impact on patient care time and tumor stage of a program for fast diagnosis and treatment of colorectal cancer. Rev Esp Enferm Dig 2010; 103: 13-19.

Received: 18-02-10.

Accepted: 17-06-10.

Correspondence: K. P. Guzmán Laura. Servei d'Epidemiologia Clínica i Salut Pública Hospital de la Santa Creu i Sant Pau. St. Antoni M. Claret 171.08041 Barcelona. e-mail: guzman_katty7@ hotmail.com

\section{INTRODUCTION}

Colorectal cancer (CRC) is second in incidence and cancer mortality in Europe (1). 26.000 new cases are diagnosed in Spain every year, and it is the second cause of death due to cancer in both sexes (2).

Relative survival at 5 years presents geographic variations. Spain has relative survival rates slightly higher than the European average (3). These variations have been attributed to the stage, histology, and tumor site, and in some countries to the time interval until diagnosis and to the quality of health services offered.

Spain and countries such as England, Canada and the United States have included in their oncology protocols preventive strategies with improved patient care (4-6), which promote fast diagnosis and treatment programs in symptomatic patients.

The objective of fast diagnosis and treatment of cancer is to reduce the diagnosis to treatment interval (DTI), that is, the time elapsed between the clinical suspicion of cancer and the final diagnosis and beginning of treatment. Among its principal motivations is to calm down patients' and relatives' anxiety, who sometimes have to put up with long waits. Besides, delays may have an influence on tumor stage and patient survival $(7,8)$.

Some studies have tried to prove that a short DTI is associated with earlier stages and greater survival rates (7-10). However, scientific evidence is controversial, possibly due to the complexity of DTI, which includes the delay attributable to the patient and to healthcare givers (9).

In Catalonia, the Fast Track Diagnosis and Treatment Program (FTDTP) was introduced in 2005 for the most incident cancers: breast, lung and colorectal. The program establishes preferential circuits between primary care and the reference hospitals, which allow for reaching periods of less than 30 days between the first contact with the hospital and the start of treatment for patients suspected of having cancer. 
In our environment there are no published studies on the effectiveness of these programs. The main objective of this study is to evaluate the effectiveness of a fast track diagnosis and treatment program for CRC in terms of DTI and tumor stage reduction. A second objective is to study the association between the DTI and the tumor stage, independently of the caregiving track.

\section{METHODS}

This is a quasi-experimental study with control group (11) that included 156 incident and primary diagnosed CRC cases who entered in the preferential track and 156 patients cared for in the habitual care track (control group). All were diagnosed and treated at the Hospital de Sant Pau. This is a tertiary teaching hospital, reference center for an area of Barcelona city with a population of 440.000 inhabitants. The FTDTP started in June 2005 in coordination with the area's primary care centers, reaching consensus on clinical criteria for high suspicion of CRC and the preferred diagnostic-therapeutic tracks (see Appendix). During this time approximately the same pro- portion of patients went through the habitual care track and not through the FTDTP because the physician responsible did not take into account the FTDTP, programming for the preferential track was busy, or there were no clinical criteria for suspecting CRC.

All patients with CRC who were seen in the FTDTP between July 2005 and December 2008 were eligible to enter the study $(\mathrm{n}=165)$. However, in order to homogenize the type of patient, those who were diagnosed and treated solely in the Emergency Room, those who were hospitalized before beginning treatment, those treated only with endoscopic polypectomy, and those with periodic colonoscopies due to risk factors were excluded. 156 patients were finally included $(94.6 \%)$.

Another 156 patients were randomly selected among those seen in the habitual care track (control group), following the same inclusion and exclusion criteria than that used for the patients in the FTDTP and frequency matched by tumor site (colon or rectum), age ( $\leq 40,41-60,61-80$ and $>80$ ), and year of admittance. It was impossible to match by year of admittance or age group in 42 patients (27\%) so it was necessary to get controls with a previous or posterior admittance year and/or higher or lower age group.

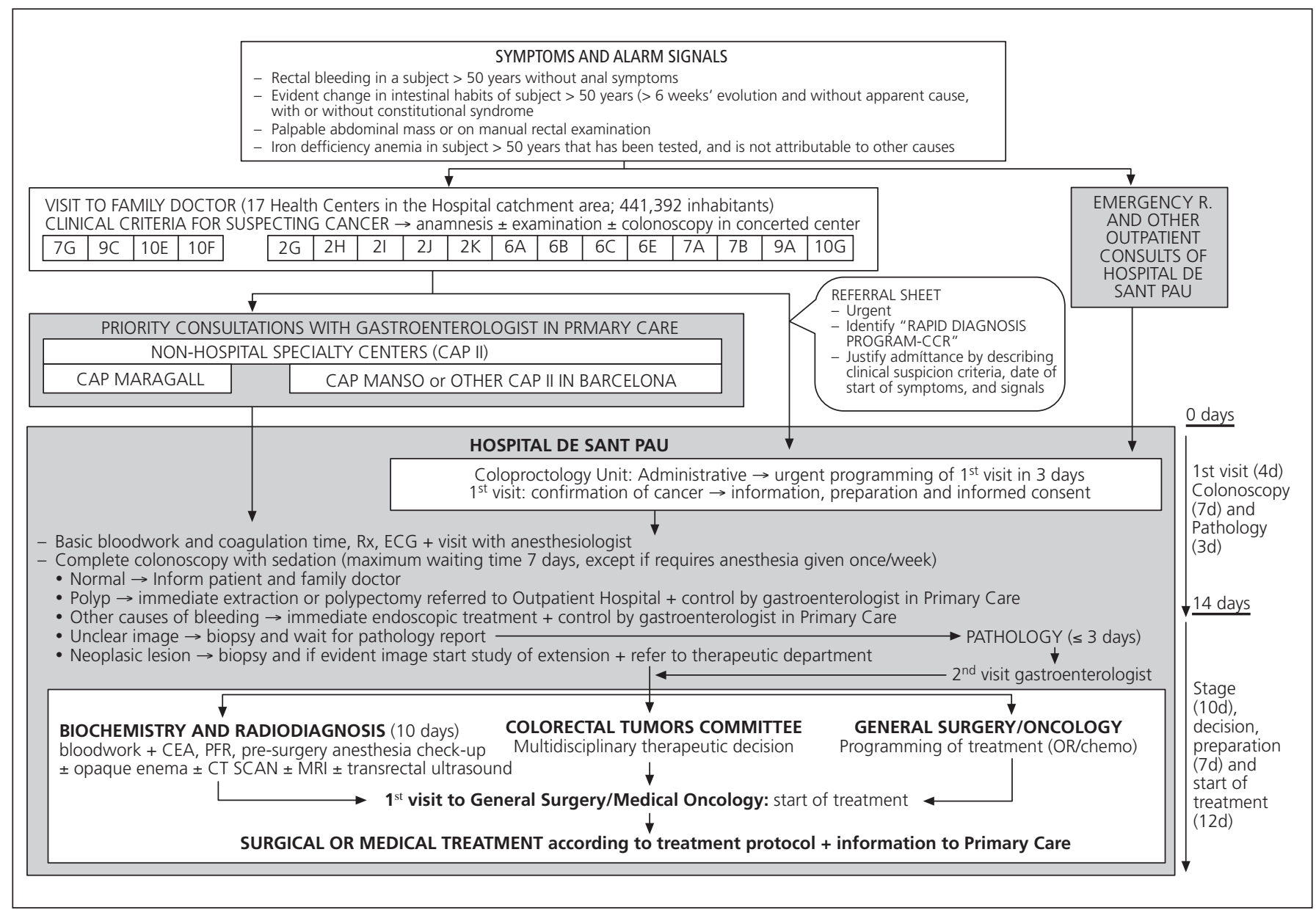

Appendix. Preferential track of the Fast Track Diagnosis and Treatment Program (FTDTP) of patients with colorectal cancer in the Hospital de Sant Pau. 


\section{Variables}

Information for both groups was collected from clinical and administrative hospital records, including pathology reports, hospital releases and the CRC committee's case registry. Basic information was collected, such as: age, sex, address, referred by whom, year of admittance, department of entry (defined as the hospital department where the first consultation for the tumor took place, grouped into Emergency Room and other departments), therapeutic department and type of treatment.

The diagnostic interval (DI) was calculated in days, from the date of setting up the first consultation for the tumor at the hospital and the date of diagnostic confirmation in the Pathology report. The therapeutic interval (TI) was calculated from the time of diagnostic confirmation until the date of the first treatment. The diagnosis to treatment interval (DTI) resulted of adding DI and TI. Tumor stage was classified according to the TNM system (12).

Colonic tumors (ascending colon, descending colon, transversal and sigmoid) were differentiated from rectal tumors (rectum-sigma and rectum), and those with a low histological grading (well and moderately differentiated) from those with a high grading (poorly differentiated and undifferentiated) (13).

\section{Statistical analysis}

Since DI, TI and DTI did not have a normal distribution a logarithmic transformation was used, and the geometric means with their $95 \%$ confidence intervals $(95 \%$ CI) are presented here (14). For the bivariate analysis t Student and chi-square tests were used.

Linear regression was used in the multivariate analysis of the association between DTI and the diagnostic-therapeutic track. Logistic regression models were also used, with DTI as a dichotomic variable ( $<30$ days $v s . \geq 30$ days).

Logistic regression was used for analyzing the influence of the diagnostic-therapeutic track and the DTI on tumor stage (0-II $v s$. III-IV), and the results were given as crude and adjusted odds ratios. Final models included significant variables $(\mathrm{p}<0.05$, potential confounding factors and clinically relevant variables).

Analysis by tumor site on the influence of DTI on tumor stage showed opposite tendencies for colonic and rectal cancer. This is why interaction between DTI and tumor site was analyzed. Analyses were done with SPSS, version 17.0 .

\section{RESULTS}

Clinical and care characteristics of FTDTP and control patients were similar, excepting sex, address and referral. A greater percentage of controls entered through the Emergency Room or other hospital departments, while FTDTP patients came in mainly through the Gastroenterology Department, since they were coming from Primary Care. Controls presented a slightly higher percentage of high grade tumors and unclassified histological grading (Table I).

Table I. Clinical and care characteristics of patients according to care track

\begin{tabular}{|c|c|c|c|c|}
\hline & & \multicolumn{2}{|c|}{ Care Track } & \\
\hline & & $\begin{array}{c}\text { FTDTP } \\
(n=156)\end{array}$ & $\begin{array}{c}\text { Control } \\
(n=156)\end{array}$ & \\
\hline & & $n(\%)$ & $n(\%)$ & $p$ \\
\hline Sex & Female & $56(35.9)$ & 79 (50.6) & 0.009 \\
\hline Age (years) & Mean (S.D.) & $71(12)$ & $72(11)$ & 0.190 \\
\hline Address & $\begin{array}{l}\text { Hospital catchment area } \\
\text { Rest of Barcelona } \\
\text { Outside of Barcelona }\end{array}$ & $\begin{array}{c}126(80.8) \\
18(11.5) \\
12(7.7)\end{array}$ & $\begin{array}{c}108(69.2) \\
19(12.2) \\
29(18.6)\end{array}$ & 0.015 \\
\hline Referred by & $\begin{array}{l}\text { Family doctor } \\
\text { Primary Care Specialist } \\
\text { Other specialists } \\
\text { Own initiative } \\
\text { Other }\end{array}$ & $\begin{array}{c}43(27.6) \\
34(21.8) \\
63(40.4) \\
13(8.3) \\
3(1.9)\end{array}$ & $\begin{array}{c}25(16.0) \\
11(7.1) \\
79(50.6) \\
35(22.4) \\
6(3.8)\end{array}$ & $<0.001$ \\
\hline $\begin{array}{l}\text { Year of } \\
\text { admittance }\end{array}$ & $\begin{array}{l}2005-2006 \\
2007-2008\end{array}$ & $\begin{array}{l}75(48.1) \\
81(51.9)\end{array}$ & $\begin{array}{l}90(57.7) \\
66(42.3)\end{array}$ & 0.089 \\
\hline $\begin{array}{l}\text { Entry } \\
\text { department }\end{array}$ & $\begin{array}{l}\text { Emergency Room } \\
\text { General Surgery } \\
\text { Gastroenterology } \\
\text { Medical Oncology } \\
\text { Other }\end{array}$ & $\begin{array}{c}16(10.3) \\
10(7.1) \\
124(88.6) \\
2(1.4) \\
4(2.9)\end{array}$ & $\begin{array}{l}42(26.9) \\
16(14.0) \\
38(33.3) \\
17(14.9) \\
21(18.4)\end{array}$ & $<0.001$ * \\
\hline Tumor site & $\begin{array}{l}\text { Colonic tumor } \\
\text { Rectal tumor }\end{array}$ & $\begin{array}{c}101(64.7) \\
55(35.3)\end{array}$ & $\begin{array}{c}100(64.1) \\
56(35.9)\end{array}$ & 0.910 \\
\hline $\begin{array}{l}\text { Histologic } \\
\text { grading }\end{array}$ & $\begin{array}{l}\text { Low grade } \\
\text { High grade } \\
\text { Unclassified }\end{array}$ & $\begin{array}{c}142(91.0) \\
10(6.4) \\
4(2.6)\end{array}$ & $\begin{array}{c}127(81.4) \\
18(11.5) \\
11(7.0)\end{array}$ & 0.041 \\
\hline $\begin{array}{l}\text { Therapeutic } \\
\text { department }\end{array}$ & $\begin{array}{l}\text { General Surgery } \\
\text { Medical Oncology } \\
\text { Other }\end{array}$ & $\begin{array}{c}138(88.5) \\
16(10.3) \\
2(1.3)\end{array}$ & $\begin{array}{c}127(81.4) \\
21(13.5) \\
8(5.1)\end{array}$ & 0.094 \\
\hline $\begin{array}{l}\text { Therapeutic } \\
\text { department }\end{array}$ & $\begin{array}{l}\text { Surgical } \\
\text { Chemotherapy or } \\
\text { chemo/radiotherapy } \\
\text { Other }\end{array}$ & $\begin{array}{c}137(87.8) \\
\\
15(9.6) \\
4(2.6)\end{array}$ & $\begin{array}{c}127(81.4) \\
21(13.5) \\
8(5.1)\end{array}$ & 0.260 \\
\hline
\end{tabular}

FTDTP: Fast Track Diagnosis and Treatment Program

S.D.: Standard deviation

*p value of the difference between patient entry through the Emergency Room and the other departments (programmed entry).

\section{Diagnosis to treatment interval and type of care track}

Mean DTI for the FTDTP group was 39.20 days, compared with 63.40 days for the control group $(\mathrm{p}<0.001)$. Significant differences were also found for the DI and TI, with a reduction of 9.60 and 7.75 days, respectively, in the FTDTP group. These differences remained when colonic and rectal tumors were analyzed separately (Table II). Multivariate analysis showed a mean DTI of 
Table II. Days of diagnosis to treatment interval tic-therapeutic interval and tumor stage according to type of care track

\begin{tabular}{|c|c|c|c|c|c|}
\hline & & & \multicolumn{3}{|c|}{ Care Track } \\
\hline & & & \multirow{2}{*}{$\begin{array}{c}\text { FTDTP } \\
(n=156)\end{array}$} & \multicolumn{2}{|l|}{$\begin{array}{l}\text { Control } \\
(n=156)\end{array}$} \\
\hline & & & & $n(\%)$ & $p$ \\
\hline $\mathrm{DI}$ & \multicolumn{2}{|c|}{ Mean $(95 \% \mathrm{Cl})^{*}$} & $\begin{array}{c}7.23 \\
(6.30-8.30)\end{array}$ & $\begin{array}{c}16.83 \\
(14.01-20.21)\end{array}$ & $<0.001$ \\
\hline $\mathrm{TI}$ & \multicolumn{2}{|c|}{ Mean $(95 \% \mathrm{Cl})^{*}$} & $\begin{array}{c}28.50 \\
(25.70-31.62)\end{array}$ & $\begin{array}{c}36.25 \\
(32.09-40.96)\end{array}$ & 0.001 \\
\hline \multirow[t]{9}{*}{ DTI } & \multicolumn{2}{|c|}{ Mean $(95 \% \mathrm{Cl})^{\star}$} & $\begin{array}{c}39.20 \\
(36.21-42.42)\end{array}$ & $\begin{array}{c}63.40 \\
(57.08-70.41)\end{array}$ & $<0.001$ \\
\hline & \multicolumn{2}{|c|}{ Stage 0 -I mean $(95 \% \mathrm{CI})^{*}$} & $\begin{array}{c}39.36 \\
(322-48,13)\end{array}$ & $\begin{array}{c}78.96 \\
(48.09-129.67)\end{array}$ & $<0.001$ \\
\hline & \multicolumn{2}{|c|}{ Stage II mean $(95 \% \mathrm{Cl})^{*}$} & $\begin{array}{c}37.75 \\
(32.46-43.95)\end{array}$ & $\begin{array}{c}64 \\
(44.34-93.39)\end{array}$ & $<0.001$ \\
\hline & \multicolumn{2}{|c|}{ Stage III mean $(95 \% \mathrm{Cl})^{*}$} & $\begin{array}{c}41.39 \\
(33.82-50.65)\end{array}$ & $\begin{array}{c}65.82 \\
(40.98-105.74)\end{array}$ & $<0.001$ \\
\hline & \multicolumn{2}{|c|}{ Stage IV mean $(95 \% \mathrm{Cl})^{*}$} & $\begin{array}{c}38.74 \\
(31.84-47.13)\end{array}$ & $\begin{array}{c}47.75 \\
(29.46-77.40)\end{array}$ & $<0.001$ \\
\hline & \multicolumn{2}{|c|}{ Colon mean $(95 \% \mathrm{Cl})$} & $\begin{array}{c}34.88 \\
(30.97-39.25)\end{array}$ & $\begin{array}{c}61.25 \\
(45.97-81.53)\end{array}$ & $<0.001$ \\
\hline & \multicolumn{2}{|c|}{ Rectum mean (95\% Cl) } & $\begin{array}{c}48.52 \\
(42.18-55.87)\end{array}$ & $\begin{array}{c}67.49 \\
(48.13-94.63)\end{array}$ & 0.001 \\
\hline & \multirow{2}{*}{\multicolumn{2}{|c|}{$\begin{array}{l}<30 \text { days } n(\%) \\
\geq 30 \text { days } n(\%)\end{array}$}} & $44(28.2)$ & $16(10.3)$ & $<0.001$ \\
\hline & & & $112(71.8)$ & $140(89.7)$ & \\
\hline Tumor & $0-1$ & $n(\%)$ & $31(19.9)$ & $27(17.3)$ & 0.69 \\
\hline \multirow[t]{3}{*}{ stage } & $\|A-\| B$ & $n(\%)$ & $52(33.3)$ & $51(32.7)$ & \\
\hline & $\|A-\| B$ & $n(\%)$ & $40(25.6)$ & $49(31.4)$ & \\
\hline & IV & $n(\%)$ & $33(21.2)$ & $29(18.6)$ & \\
\hline
\end{tabular}

FTDTP: Fast Track Diagnosis and Treatment Program

DI: diagnostic interval, TI: therapeutic interval, DTl: diagnosis to treatment interval

*Geometric mean and $95 \%$ confidence interval in days.
23.10 days (95\% CI: 14.76-36.13) in FTDTP patients, while the control group required a mean of 39.09 days (95\% CI: 21.52-70.95; $\mathrm{p}<0.001$ ). Results according to site and tumor stage showed a greater DTI in the control group for all sites and stages $(\mathrm{p}<0.001)$. However, a slightly higher DTI was observed for colonic tumors in an advanced stage, while rectal tumors in an advanced stage showed a lower DTI (non-significant difference, $\mathrm{p}$ $=0.25$ ).

Only $28 \%$ of FTDTP patients reached a DTI of less than 30 days, and for the control group that percentage was only $10 \%$ (Table II). Multivariate analysis showed that the control group had a probability almost 5 times higher of having a DTI greater than 30 days with respect to the FTDTP group. Other determinants of a DTI greater than 30 days were year of admittance (greater delay in the 2007-2008 period) and tumor site (greater delay for rectal cancer) (Table III).

\section{Tumor stage and type of care track}

No significant differences were found for tumor stage in the FTDTP and control groups: $21.2 \%$ of the FTDTP group and 18.6 of the control group had a stage IV (Table II). Analysis by tumor site also did not show any significant differences for colonic tumors $(\mathrm{p}=0.72)$ or rectal tumors $(p=0.62)$. Multivariate analysis confirmed these results (Table IV).

\section{Tumor stage and diagnosis to treatment interval}

The relation between DTI and tumor stage, independently of the care track, also did not show significant differences. The mean DTI in patients with stages 0-II and

Table III. Risk determinants for a diagnosis to treatment interval greater than $\mathbf{3 0}$ days

\begin{tabular}{|c|c|c|c|c|c|}
\hline & \multicolumn{5}{|c|}{ DIAGNOSIS TO TREATMENT INTERVAL > 30 DAYS } \\
\hline & & $\operatorname{cOR}(95 \% \mathrm{Cl})$ & $p$ & $\mathrm{aOR}(95 \% \mathrm{Cl})$ & $P$ \\
\hline Care track & $\begin{array}{l}\text { FTDTP } \\
\text { Control }\end{array}$ & $\begin{array}{c}1 \\
3.44(1.84-6.41)\end{array}$ & $<0.001$ & $\begin{array}{c}1 \\
4.94(2.24-10.90)\end{array}$ & $<0.001$ \\
\hline Sex & $\begin{array}{l}\text { Male } \\
\text { Female }\end{array}$ & $\begin{array}{c}1 \\
1.40(0.79-2.51)\end{array}$ & 0.251 & $\begin{array}{c}1 \\
1.02(0.99-1.05)\end{array}$ & 0.334 \\
\hline Age (years) & & $1.01(0.99-1.04)$ & 0.204 & $1.02(0.99-1.05)$ & 0.135 \\
\hline Year of admittance & $\begin{array}{l}2005-2006 \\
2007-2008\end{array}$ & $\begin{array}{c}1 \\
1.70(0.95-3.04)\end{array}$ & 0.071 & $\begin{array}{c}1 \\
2.37(1.24-4.53)\end{array}$ & 0.009 \\
\hline Entry department & $\begin{array}{l}\text { Programmed } \\
\text { Emergency }\end{array}$ & $\begin{array}{c}1 \\
0.61(0.34-1.10)\end{array}$ & 0.098 & $\begin{array}{c}1 \\
1.58(0.74-3.35)\end{array}$ & 0.239 \\
\hline Tumor site & $\begin{array}{l}\text { Colon } \\
\text { Rectum }\end{array}$ & $\begin{array}{c}1 \\
5.32(2.33-12.17)\end{array}$ & $<0.001$ & $\begin{array}{c}1 \\
7.17(3.00-17.19)\end{array}$ & $<0.001$ \\
\hline Tumor stage & $\begin{array}{l}0-\| \\
\| I-I V\end{array}$ & $\begin{array}{c}1 \\
1.09(0.62-1.92)\end{array}$ & 0.765 & $\begin{array}{c}1 \\
1.44(0.76-2.73)\end{array}$ & 0.260 \\
\hline
\end{tabular}

cOR: crude odds ratio, aOR: odds ratio adjusted by all the variables in the table; $95 \% \mathrm{Cl}: 95 \%$ confidence interval. 
Table IV. Risk determinants for a III-IV tumor stage

\begin{tabular}{|c|c|c|c|c|c|}
\hline & \multicolumn{5}{|c|}{ TUMOR STAGE III-IV } \\
\hline & & $\operatorname{cOR}(95 \% \mathrm{Cl})$ & $p$ & $\mathrm{aOR}(95 \% \mathrm{Cl})$ & $P$ \\
\hline Care track & $\begin{array}{l}\text { FTDTP } \\
\text { Control }\end{array}$ & $\begin{array}{c}1 \\
1.14(0.73-1.77)\end{array}$ & 0.57 & $\begin{array}{c}1 \\
0.64(0.36-1.14)\end{array}$ & 0,13 \\
\hline DTI & $\begin{array}{l}<30 \text { days } \\
\geq 30 \text { days }\end{array}$ & $\begin{array}{c}1 \\
1.09(0.62-1.92)\end{array}$ & 0.77 & $\begin{array}{c}1 \\
1.25(0.64-2.43)\end{array}$ & 0,51 \\
\hline Age & $\begin{array}{l}<65 \text { years } \\
65 \text { to } 75 \text { years } \\
>75 \text { years }\end{array}$ & $\begin{array}{c}1 \\
1.12(0.61-2.06) \\
0.72(0.42-1.26)\end{array}$ & 0.24 & $\begin{array}{c}1 \\
1.31(0.68-2.53) \\
0.69(0.37-1.27)\end{array}$ & 0,09 \\
\hline Year of admittance & $\begin{array}{l}2005-2006 \\
2007-2008\end{array}$ & $\begin{array}{c}1 \\
0.66(0.42-1.03)\end{array}$ & 0.06 & $\begin{array}{c}1 \\
0.58(0.35-0.95)\end{array}$ & 0,03 \\
\hline Histologic grading & $\begin{array}{l}\text { Low grade } \\
\text { High grade }\end{array}$ & $\begin{array}{c}1 \\
2.54(1.11-5.83)\end{array}$ & 0.03 & $\begin{array}{c}1 \\
2.22(0.92-5.35)\end{array}$ & 0,07 \\
\hline Tumor site & $\begin{array}{l}\text { Colon } \\
\text { Rectum }\end{array}$ & $\begin{array}{c}1 \\
0.77(0.48-1.22)\end{array}$ & 0.26 & $\begin{array}{c}1 \\
0.59(0.33-1.03)\end{array}$ & 0,06 \\
\hline Entry department & $\begin{array}{l}\text { Programmed } \\
\text { Emergency }\end{array}$ & $\begin{array}{c}1 \\
0.60(0.38-0.94)\end{array}$ & 0.03 & $\begin{array}{c}1 \\
0.63(0.35-1.10)\end{array}$ & 0,11 \\
\hline Type of treatment & $\begin{array}{l}\text { Surgery } \\
\text { Chemotherapy* } \\
\text { Other }\end{array}$ & $\begin{array}{c}1 \\
2.16(1.05-4.44) \\
3.66(0.97-13.81)\end{array}$ & 0.02 & $\begin{array}{c}1 \\
2.44(1.07-5.59) \\
5.10(0.92-28.38)\end{array}$ & 0,02 \\
\hline
\end{tabular}

COR: crude odds ratio, aOR: odds ratio adjusted by all the variables in the table; $95 \% \mathrm{Cl}$ : $95 \%$ confidence interval, FTDTP: Fast Track Diagnosis and Treatment Program, DTI: diagnosis to treatment interval; * Or chemo/radio-therapy

III-IV was 45.60 and 46.62 days, respectively $(\mathrm{p}=0.81)$. Patients with a DTI greater than 30 days did not show a higher risk for an advanced tumor stage (Table IV). However, for colonic tumors the risk for an advanced tumor stage tended to increase in patients with a DTI $>30$ days, while for rectal tumors the risk tended to decrease $(\mathrm{p}=$ 0.053 ) for the interaction between tumor site and DTI (Fig. 1).

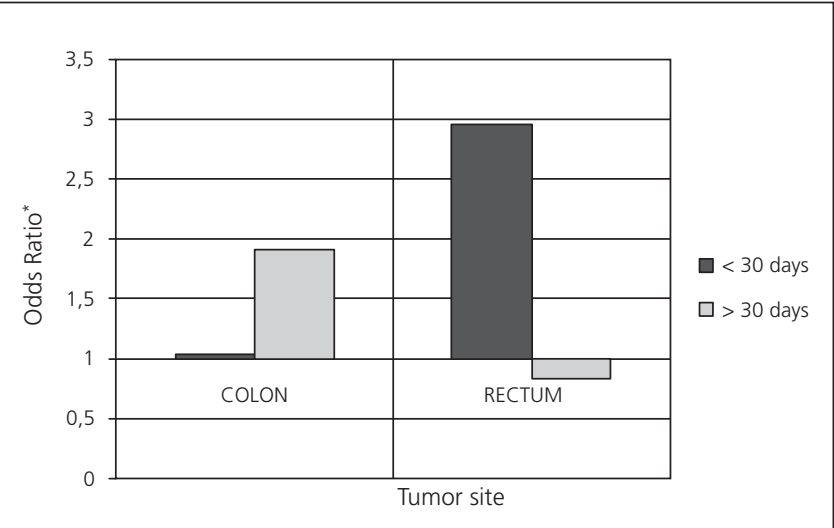

Fig. 1. Estimated risk for a tumor stage III-IV according to diagnosis to treatment interval and tumor site. ${ }^{*}$ Odds ratio for a III-IV tumor stage in colonic cancer with a DTI < 30 days, adjusted by care track, age in years, year of admittance, histological grading, entry department and type of treatment.

\section{DISCUSSION}

Since the introduction of FTDTP no study has assessed its effectiveness in terms of a decrease in the DTI or tumor stage. The assessment of FTDTP by means of clinical-administrative records allowed for the obtainment of valid data, especially dates and clinical aspects of the care process, thus avoiding recall bias faced by other studies on the subject.

The patients in the FTDTP and control groups showed differences in some of the study variables that could be attributed to the characteristics inherent in the program, which focuses on subjects seen on an outpatient basis, and on the coordination between primary care and the hospital. As a consequence, there could exist clinical differences related to the fact of having entered the FTDTP or the habitual care track. For example, the physician could have used FTDTP more frequently for young patients, with a recent clinical expression, or with greater possibility of cure. However, tumor stages were practically the same in both groups, and we believe that entering the FTDTP was not connected to clinical aspects but to the knowledge and use of the program by the physician and to available space for consultations and tests.

A previous study in the same health setting (15) reported a median DTI of 25 days, and $41.7 \%$ of patients showed a delay of more than 30 days, being the delay greater in tertiary hospitals. In this study DTI was calcu- 
lated from the date of the first diagnostic examination to the beginning of treatment, which is a shorter period that the one from our study. Another Spanish study found a global diagnostic delay of 185 days, of which 119 were attributed to the patient's delay in visiting the physician, 38 to the physician (time until the endoscopy is requested), and 28 to the health administration (time elapsed between the request for an endoscopy and when it was done) (16). Other three studies used the same definition of DTI as in our study. One was done in Canada with patients who were candidates for surgical resection, and found a median of 29 days (17). The other two are from the United Kingdom $(18,19)$ and were done in the context of a rapid diagnosis plan ("Two Week Rule"). They reported medians of 50 to 73.5 days for patients in the preferential track and 126.5 to 140 days for other tracks. Our mean of 39 days is within the range of published results. None of the studies found a significant association between delay and tumor stage, the same as we have found in our study.

Tumor stage is known to be the most important prognostic factor in CRC (20). Our working hypothesis assumed an influence of the care track on tumor stage mediated by DTI. However, our results, as those of other authors, do not support this hypothesis. Gómez-Domínguez et al. concluded that the diagnostic delay calculated from the beginning of symptoms until tumor diagnosis and obtained through a personal interview, did not have an influence on the tumor's extension (16). Moreover, the most important delay was attributed to the patient, and in no case did the physician's or hospital's delay have an influence on the tumor stage. Our results could be explained by the fact that the decrease in the DTI obtained with FTDTP is small (16 days less, according to the multivariate analysis) and in a low proportion of patients (28\% of FTDTP patients with DTI < 30 days), so it would not have a biological impact on the tumor with a consequent reduction of the stage.

It would be interesting to study the clinical effect of other programs that achieve greater reductions of the DTI and in a larger number of patients. Additionally, the program does not interfere with other periods of the natural history of the disease, like the asymptomatic period or the time from the start of symptoms until the patient seeks medical help, which as Gómez-Domínguez et al. point out, is the period that most contributes to total delay (16). All of these periods are conditioned by tumor's biology, host response, diagnostic precision, effectiveness of treatment and patient attitudes (21).

The longer DTI found for rectal tumors could be explained by the greater number of complementary tests done for this site (13). We have observed an inverse association between DTI and tumor stage in colonic and rectal tumors. Thus, DTIs $>30$ days in colonic cancer were associated with later stages whereas for rectal cancers they were associated with earlier stages. This could be related to the different nature of the two cancers. There is evidence of a more aggressive evolution of rectal adeno- mas into carcinomas (22), and rectal tumors in advanced stages present a more striking clinical expression than colonic tumors. This could explain their early presentation with advanced stages, as other authors have suggested (10). However, this is contrary to the hypothesis of an association between DTI and the prognosis of the disease in terms of tumor stage.

The published literature on the subject is heterogeneous, emphasizing studies that found an association between the interval from the start of symptoms until treatment, and tumor stage in rectal tumors but not in colonic tumors (10, 23-26). In Denmark, LH Iversen et al. found that for rectal tumors a total delay of 60 days or more from the start of symptoms until treatment was associated with a $69 \%$ higher risk of mortality, in comparison with a delay of less than 60 days (10). However, when separately analyzing provider's delay (interval between the first contact with the physician and treatment) or hospital's delay (interval between referral to a hospital and treatment) there were no significant differences observed in mortality. This last interval, hospital, would be the one corresponding to FTDTP.

Despite the fact that tumor stage is not determined by the care track or DTI, the achieved decrease in DTI represents an improvement in the quality of care given to the oncology patient (27). For the health system it represents a better hospital organization and coordination between care levels. A lesser delay has also been associated with a decrease in the morbidity/mortality of emergency interventions in these patients (28).

A decrease in DTIs is the responsibility of health systems, and the development of preferential tracks requires administrative support, diagnostic and therapeutic capacity, and availability of trained personnel. But it especially requires coordination between primary care and hospital teams, an adequate management of available resources, and the substitution of the fragmented and sequential functioning of the process with an integrated, parallel system (29).

In conclusion, FTDTP reduces the time of care given and probably also the anxiety of patients and relatives. In spite of this, we are still far from achieving the DTI $<30$ days for the majority of patients, as our oncology plans recommend. The achieved reduction of delay is not enough to obtain earlier tumor stages and the multifactorial nature of CRC prognosis minimizes the clinical impact of FTDTP. Therefore, the benefits of FTDTP are better framed in the area of healthcare quality than in the clinical prognosis of the patient.

\section{REFERENCES}

1. Ferlay J, Autier P, Boniol M, Heanue M, Colombet M, Boyle P. Estimates of the cancer incidence and mortality in Europe in 2006. Ann Oncol 2007; 18: 581-92.

2. Ministerio de Sanidad y Consumo (España). La situación del cáncer en España. Madrid: Instituto de Salud Carlos III; 2005.191 p. 
3. Santa M, Allemania C, Santaquilanib M, Knijnb A, Marchesia F, Capocacciac R. EUROCARE-4: Survival of cancer patients diagnosed in 1995-1999-results and commentary. Eur J Cancer 2009; 45: 931-91.

4. Department of Health (England). The NHS cancer plan: a plan for investment, a plan for reform. London: Department of Health; 2000. $97 \mathrm{p}$

5. Paterson W, Depew W, Paré P, Petrunia D, Switzer C, Veldhuyzen van Zanten S, et al; Canadian Association of Gastroenterology Wait Time Consensus Group. Canadian consensus on medically acceptable wait times for digestive health care. Can J Gastroenterol 2006; 20(6): 411-23.

6. Freund K, Battaglia T, Calhoun E, Dudley D, Fiscella K, Paskett E, et al. National Cancer Institute Patient Navigation Research Program: methods, protocol, and measures. Cancer 2008; 113(12): 3391-9.

7. Ramos M, Esteva M, Cabeza E, Llobera J, Ruiz A. Lack of association between diagnostic and therapeutic delay and stage of colorectal cancer. Eur J Cancer 2008; 44: 510-21.

8. Ramos M, Esteva M, Cabeza E, Campillo C, Llobera J, Aguiló A. Relationship of diagnostic and therapeutic delay with survival in colorectal cancer: a review. Eur J Cancer 2007; 43: 2467-78.

9. Porta M, Gallen M, Malats N, Planas J. Influence of diagnostic delay upon cancer survival: an analysis of five tumours sites. J Epidemiol Community Health 1991; 45(3): 225-30.

10. Iversen L, Antonsen S, Laurberg S, Lautrup M. Therapeutic delay reduces survival of rectal cancer but not of colonic cancer. Br J Surg 2009; 96: 1183-9.

11. Cook TD, Campbell DT. Quasi-Experimentation: Design and Analysis Issues for Field Settings. Chicago:Rand McNally; 1979.

12. Colon and rectum. In: American Joint Committee on Cancer: AJCC Cancer Staging Manual. 6 ${ }^{\text {th }}$ ed. New York, NY: Springer; 2002. p.113-124.

13. OncoGuía de colon y recto. Barcelona: Agència d'Avaluació de Tecnologia i Recerca Mèdiques. CatSalut. Departament de Sanitat i Seguretat Social. Generalitat de Catalunya. Noviembre 2003 (OG03/2003)

14. Bland M, Altman D. Transformations, means, and confidence intervals. BMJ 1996; 312: 1079.

15. Pérez G, Porta M, Borrell C, Casamitjana M, Bonfill X, Bolibar I, et $\mathrm{al}$; INTERCAT study group. Interval from diagnosis to treatment onset for six major cancers in Catalonia, Spain. Cancer Detect Prev 2008; 32: 267-75

16. Gómez-Domínguez E, Trapero-Marugán M, Del Pozo A, Cantero J, Gisbert J, Maté J. Factores pronósticos en carcinoma colorectal. Im- portancia de la demora diagnóstica. Rev Esp Enferm Dig 2006; 98(5): 322-9.

17. Simunovic M, Gagliardi A, McCready D, Coates A, Levine M, DePetrillo D. A snapshot of waiting times for cancer surgery provided by surgeons affiliated with regional cancer centres in Ontario. CMAJ 2001; 165 (4): 421-5.

18. Bevis P, Donaldson O, Card M, Durdey P, Thomas M, Sylvester P, et al. The association between referral source and stage of disease in patients with colorectal cancer. Colorectal Dis 2007; 10: 58-62.

19. Trickett J, Donaldson D, Bearn P, Scott H, Hassall A. A study on the routes of referral for patients with colorectal cancer and its affect on the time to surgery and pathological stage. Colorectal Dis 2004; 6: 428-31.

20. Kronborg O. Staging and surgery for colorectal cancer. Eur J Cancer 1993; 29A(4): 575-83.

21. Porta M, Belloc J, Mallats N. Estudios españoles sobre la demora diagnóstica y terapéutica en el cáncer. Un análisis crítico de su metodología y resultados. En: Porta M, Alvarez-Dardet C, editores. Revisiones en Salud Pública. Vol.1. Barcelona: Masson; 1989. p. 197-226.

22. Smith D, Ballal M, Hodder R, Selvachandran S, Cade D. The adenoma carcinoma sequence: an indoctrinated model for tumorigenesis, but is it always a clinical reality? Colorectal Dis 2006; 8(4): 296-301.

23. Ristvedt SL, Birnbaum EH, Dietz DW, Fleshman JW, Kodner IJ, Read TE. Delayed treatment for rectal cancer. Dis Colon Rectum 2005; 48: 1736-41.

24. Langenbach MR, Schmidt J, Neumann J, Zirngibl H. Delay in treatment of colorectal cancer: multifactorial problem. World J Surg 2003; 27:304-8.

25. Korsgaard M, Pedersen L, Sørensen HT, Laurberg S. Delay of treatment is associated with advanced stage of rectal cancer but not of colon cancer. Cancer Detect Prev 2006; 30(4): 341-6.

26. Arbman G, Nilsson E, Störgren-Fordell V, Sjödahl R. A short diagnostic delay is more important for rectal cancer than colonic cancer. Eur J Surg 1996; 162: 899-904.

27. Weisman A, Worden J. The existential plight in cancer: significance of the first 100 days. Int J Psychiatry Med 1976-1977; 7(1): 1-15.

28. Mulcahy H, O'Donoghue. Duration of colorectal cancer symptoms and survival: the effect of confounding clinical and pathological variables. Eur J Cancer 1997; 33(9): 1461-7.

29. Bixquert Jiménez M. Early diagnosis of colorectal cancer. Diagnostic delay reduction or rather screening programs? [editorial]. Rev Esp Enferm Dig 2006; 98(5): 315-21. 